\title{
UM DISPOSITIVO CONECTOR - RELATO DA EXPERIÊNCIA DO PAI-PJ/TJMG, UMA POLÍTICA DE ATENÇÃO INTEGRAL AO LOUCO INFRATOR, EM BELO HORIZONTE
}

\author{
A CONNECTING DEVICE - REPORT OF EXPERIENCE OF \\ PAI-PJ/TJMG A POLICY FOR THE FULL ATTENTION TO THE \\ INSANE LAWBREAKER IN BELO HORIZONTE
}

Fernanda Otoni de Barros-Brisset ${ }^{1}$

Fernanda Otoni de Barros-Brisset. Um dispositivo conector - Relato da experiência do PAI-PJ/TJMG, uma política de atenção integral ao louco infrator, em Belo Horizonte. Rev Bras Crescimento Desenvolv Hum. 2010; 20(1): 116-128

\section{Resumo:}

O presente artigo buscou demonstrar que as soluções de sociabilidade só podem ser alcançadas quando o portador de sofrimento mental conta com a secretaria de um programa complexo e multifacetado, que não se constrói a poucas mãos, nem em pouco tempo. É preciso estar atento às soluções de sujeito e suas conexões às contribuições dos mais diversos segmentos, na promoção da ampliação dos laços de sociabilidade dos loucos infratores nos interstícios e nas vias principais de suas relações de convivência. O Programa PAI-PJ, como um dispositivo conector, demonstra essa possibilidade.

Palavras-chave: segurança; competência clínica; política social.

\section{Abstract:}

This study attempts to show that solutions of sociability can only be achieved when the patient with mental disorders counts with the secretary of a complex and multifaceted program which is not built by a few hands, or in a short time. We must be aware of the solutions of the subject and its connections to the contributions of the various segment of the society, in promoting the expansion of ties of sociability of the insane offenders in the interstices and on the main roads of their relations of coexistence. The Program PAI-PJ, as a connecting device, demonstrates this possibility.

Key words: security; clinical competence; public policy.

Recorte da monografia vencedora do eixo diretrizes para o sistema penitenciário, no concurso promovido por ocasião da I CONSEG. Sua publicação integral pode ser lida em: BRISSET-BARROS, F.O. Por uma política de atenção integral ao louco infrator. Belo Horizonte: Del Rey. 2009. (no prelo).

1 Psicanalista (EBP/AMP). Doutora em Ciências Humanas: Sociologia e Política (UFMG) Coordenadora Clinica do Programa de Atenção Integral ao Paciente Judiciário (PAI-PJ-TJMG). Professora do Departamento de Psicologia e Direito da PUC-Minas Correspondência para: fernanda.otoni@terra.com.br 


\section{1 - A INVENÇÃO DE UMA EXPERIÊNCIA INOVADORA}

No apagar das luzes do século XX, em novembro de 1999, iniciou-se uma mobilização política, social e intersetorial no sentido de tornar pública a violação dos direitos humanos aplicada institucionalmente aos loucos infratores. Ao mesmo tempo, buscavam-se alternativas e referências para enfrentar a complexidade em questão, propostas inovadoras para o redesenho da política de atenção ao louco infrator.

A responsabilidade desse pontapé inicial coube à Campanha do Conselho Federal de Psicologia (CFP), que levantou a bandeira: “Manicômio Judiciário... o pior do pior...”. Seu lançamento aconteceu na abertura do IV Encontro Nacional da Luta Antimanicomial, em Maceió. O presidente da comissão de Direitos Humanos do CFP, Marcus Vinícius de Oliveira, ao abrir os trabalhos da mesa, apresentou um relatório detalhado das inúmeras violações de direitos dos loucos infratores, no Estado Brasileiro, descortinando o cenário político que a campanha teria que enfrentar.

Em seguida, o Professor Virgílio Mattos apresentou as conclusões do seu livro recémlançado, "Trem de Doido", em que discorre sobre a realidade jurídica e institucional dos loucos infratores, lançando pertinentes reflexões sobre essa complexa questão. Orientado pelas pesquisas da sua dissertação de mestrado, dedicada ao estudo das medidas de segurança no Brasil, pôde visitar os acervos do Manicômio Judiciário Jorge Vaz e a própria instituição e, a partir do que registrou, fez um relato contundente de sua indignação. ${ }^{\text {a }}$

Logo em seguida, a palavra foi passada à psicanalista e psicóloga judicial, Fernanda
Otoni de Barros, para que expusesse os resultados de sua pesquisa, realizada durante aquele mesmo ano. Essa pesquisa reuniu o levantamento da situação jurídica, clínica e social de 15 processos criminais envolvendo loucos infratores, na comarca de Belo Horizonte. A pesquisadora propôs que esses casos fossem acompanhados, em caráter experimental, por uma equipe multidisciplinar, que ficaria responsável pelo acompanhamento de um projeto individualizado, construído em parceria com diversas instituições envolvidas, como instituições de saúde mental da rede pública, Ministério Público e autoridade judicial. A novidade é que esse projeto era desenhado de acordo com os princípios da reforma psiquiátrica e dos direitos humanos, orientados pela singularidade de cada caso, e a principio nasceu apoiada pela lei estadual 11.802/1995, lei que inaugurou os pilares normativos para o redesenho da assistência em saúde mental em Minas Gerais.

\section{1- O contexto da pesquisa que antecedeu a proposição de um projeto.}

No primeiro semestre de 1999, primeira fase da pesquisa, realizamos o estudo de 15 processos, para identificar os principais problemas em torno do tratamento jurisdicional aplicado ao louco infrator. Na segunda fase, a pesquisa se dedicou a desenhar um projeto de acompanhamento dos casos na rede pública de saúde, buscando construir uma mediação entre o tratamento e o processo jurídico. ${ }^{\mathrm{b}}$

Os primeiros dados recolhidos revelaram a violação dos direitos dos indivíduos encarcerados no manicômio judiciário, além do fato que o único manicômio judiciário mineiro, o Manicômio Judiciário Jorge Vaz, àquela época, havia fechado suas portas para a entrada de novos pacientes judiciários. Este fato não dei-

MATTOS, V. Trem de Doido - O Direito Penal e a Psiquiatria de mãos dadas. Belo Horizonte: UNA Editoria. 1999.

Artigos de alunos que colaboraram com a pesquisa podem ser lidos em: BARROS, F.O. (Org). Contando Causo. Belo Horizonte: Del Rey, 2000. 
xará alternativa aos juízes criminais que não fosse encaminhar os pacientes judiciários, os loucos infratores, para serem internados nos hospitais da rede pública de saúde. Essa solução é prevista em lei, como informa o artigo 96 do código penal, que diz que a internação deve ocorrer em hospital de custódia e tratamento ou, na falta deste, em outro estabelecimento adequado. A Justiça mineira, seguindo a orientação normativa, passou a encaminhar aos hospitais psiquiátricos da FHEMIG (Fundação Hospitalar do Estado de Minas Gerais) ofícios exigindo a internação, por tempo indeterminado, dos pacientes sub-judice.

Vanessa Figueiredo Costa publicou pesquisa em que relata que o ano de 1999 se destacou na história do Instituto Raul Soares (IRS), hospital psiquiátrico da rede FHEMIG, pois foi registrado, apenas naquele ano, um aumento de 300\% nas internações de uma categoria especial de pacientes - os pacientes judiciários: "os que cometeram ato homicida e cuja internação ocorreu através de ordem judicial."”

Essa situação foi responsável pelo tensionamento entre os hospitais psiquiátricos e os juízes criminais, pois a determinação judicial de internação desses indivíduos, por tempo indeterminado, contrariava a vontade política dos gestores em saúde mental, que estavam, àquela época, cuidando do processo de desospitalização dos portadores de sofrimento mental, de acordo com o projeto de saúde mental do município.

O diagnóstico desse conflito entre saúde e justiça foi uma das constatações iniciais da primeira fase da pesquisa e apontou para a necessidade de se construir uma solução mediadora. Em julho de 1999, constituímos uma comissão no IRS. Essa comissão era composta por técnicos da saúde, da justiça e do Ministério Público, dentre outros interessados no tema. Seu objetivo era estudar os casos encaminhados por determinação judicial, para que eles recebessem um acompanhamento clínico e social que estivesse orientado pela singularidade de cada sujeito em particular, considerando os princípios da luta antimanicomial; por outro lado, esperava-se que essa alternativa também permitisse à autoridade judicial executar a sanção penal individualizada referente aos loucos infratores.

A pesquisa identificava que era preciso inventar um dispositivo conector entre a justiça e a saúde, capaz de integrar, na condução de cada caso, as lógicas heterogêneas, discursivas e práticas, atuantes na interface do tratamento do louco infrator. Esse dispositivo conector teria por compromisso a mediação entre o tratamento em saúde mental e o processo jurídico, zelando para que a solução interinstitucional estivesse de acordo com a singularidade clínica, jurídica e social de cada caso. A orientação dessa mediação seguia pistas que o paciente judiciário entregava nos espaços institucionais que passara a frequentar, na justiça ou na rede de saúde.

\section{2 - A metodologia de atenção integral: Um} acompanhamento atento às soluções do sujeito no tratamento de seu sofrimento e às suas pequenas invenções de sociabilidade Tínhamos por hábito produzir, semanalmente, uma espécie de roda de conversa, um encontro entre os diversos atores presentes na rede de atenção aos casos em andamento, para recolhermos as pistas de sujeito deixadas pelos pacientes judiciários que acompanhávamos. Dessa conversa entre os vários agentes, seguimos desenhando, desfazendo e reinventando o mapa em movimento dos acompanhamentos.

Os redesenhos produzidos junto aos vários atores dos acompanhamentos, durante as rodas de conversa, eram apresentados a operadores do direito, buscando verificar a validade jurídica daqueles novos arranjos. Caso parecessem sustentáveis, encaminhávamos relatório à autoridade judicial responsável pelo caso. Essa prática de cunhagem de um projeto viável oferecia certo mapa que nos indicava por onde pas- 
sar com a singularidade clínica e social do paciente judiciário, dentro do mundo jurídico. Aprendemos que o texto jurídico é um conjunto de normas e que poderíamos localizar uma possibilidade de encontrar, entre elas, um lugar para a causa de cada sujeito em particular.

Buscávamos construir uma orientação para os acompanhamentos e não tínhamos nenhuma prática anterior que nos indicasse uma receita. Sabíamos, através de nossos estudos sobre a clínica da psicose, de orientação lacaniana, que o crime de homicídio cometido na psicose, de modo geral, é conceitualmente uma passagem ao ato que tenta solucionar um sofrimento insuportável psiquicamente: tratase de uma resposta para a angústia, quando o sujeito se desconecta do mundo.

Contudo, nós nos perguntávamos: como tratar esse sofrimento de modo que em cada sujeito pudesse surgir uma nova resposta, como construir alguns recursos que dispensassem o ato homicida e a violência como únicas respostas e produzissem algum modo de conexão, de laço social razoável? A saída tradicional era presumir ali um sujeito intrinsecamente perigoso e segregá-lo aos porões da loucura por tempo indeterminado. Na prática histórica, constatamos que, na maior parte das vezes, aquilo significava a ‘impossível' prisão perpétua do código penal brasileiro.

"Eu tinha pra mim que o isolamento desses casos era um dos grandes responsáveis por reduzir as possibilidades de inventar respostas singulares, institucionais e políticas, em condições de produzir novos instrumentos para tratar a perturbação mental insuportável e conectar o sujeito, portador de sofrimento mental, à rede social com a qual precisou romper por não encontrar nela nenhum modo de sossegar seu sofrimento. De alguma forma, apostava que, para além da solução do isolamento, haveria outras formas mais vivas de contornar esse traumatismo.”2

Estávamos autorizados, a partir da crise que ali se instalava, a dispensar as soluções anteriores e a buscar novas saídas. Podíamos, por aquela brecha aberta, arriscar-nos a construir uma prática inédita em cada caso, a partir do saber do sujeito, acompanhando as respostas que ele mesmo entregava em diversos momentos do seu acompanhamento.

Logo de início, confirmamos que não se avança no acompanhamento desses casos, sem um espaço de convivência orientado. Para sustentar uma prática orientada pelo saber do sujeito sobre a resposta que trata seu sofrimento, não poderíamos isolar o paciente judiciário, precisávamos nos colocar ali, ao seu lado, secretariando-o, recolhendo as pistas de sua solução singular de tratamento e sociabilidade.

Presumíamos que havia um sujeito entre o paciente e o judiciário, entre o louco e o infrator. Seguir suas pistas nos levaria a algum lugar. Apostávamos que o singular de cada sujeito não poderia ser reduzido à semântica dos vocábulos, paciente judiciário - louco infrator, tão carregados dos sentidos construídos historicamente. Aos poucos fomos levados a considerar que aquele sujeito indefinível poderia ser portador de um potencial de respostas inéditas, impensáveis e razoáveis.

A experiência que inventávamos presumia que a solução se apresentaria no espaço da convivência e não no silêncio do isolamento consentido pela presunção da periculosidade. A lógica era outra. Precisaríamos recolher da convivência o que ali poderia se apresentar como uma pista sobre o que provocava o embaraço, o que despertava sua angústia, que artifícios e soluções poderiam produzir saídas para a angústia ... Eram as respostas de sujeito que serviam de guia quanto a uma possível via de construção de um laço social razoável, no tempo em que era acompanhado por muitos, no cumprimento de sua sanção penal, a medida de segurança.

Através da atenção dispensada ao percurso singular daqueles indivíduos, tivemos a compreensão de que é fundamental atribuir consequência às suas respostas. Começávamos a perceber, ainda que de modo 
muito inicial, que o ato-crime tinha consequências sobre cada um daqueles acompanhados pela pesquisa. Responder pelo seu crime diante do Juiz; demonstrar para sua cidade e sua família que tinha respondido “direito" pelo crime que cometeu, de acordo com a lei; estas eram respostas que começavam a se apresentar com certa regularidade nas falas e nos comportamentos daquelas pessoas. Parecia, enfim, cada um do seu modo, que estavam verdadeiramente envolvidos num trabalho muito particular de construir algum sentido para o sem sentido de seu ato, ensejando encontrar um apoio para o que emergiu estranho de si mesmo, inscrevendo essa esquisitice no mundo, e isso significava consentir com a medida penal que se inscreve no social, inscrita no código penal, dirigida a todos que cometem crimes.

Parecia ser muito importante no tratamento de cada um arrumar um modo de alojar, na sua relação com os outros, uma resposta em relação ao ato que praticaram, uma resposta reconhecida como socialmente válida, principalmente. Um deles, o F.J., disse assim: "Estou no hospital agora, tratando da minha doença, mas quando vou pagar pelo que fiz? Tenho que pagar pelo crime que cometi para que todos na minha cidade me recebam de volta. Só depois de cumprir a minha pena, poderei voltar para a sociedade.” F.J. escrevia nuns papeizinhos pequenos relatos do seu crime, da sua esquisitice; dizia que escrevia para não esquecer quando fosse falar com o Juiz.

Pareceu-nos, logo de início, que inscrever na ordem do mundo a resposta fora da lei, ao responder pelo seu ato esquisito, podia ser um caminho para encontrar um jeito de ser recebido nessa ordem social de um jeito razoável. Encontrar-se com o dispositivo jurídico, submeter-se aos seus procedimentos, foi se revelando como um dos recursos humanizantes essenciais para restaurar o laço social que se rompeu com o crime.
A periculosidade foi perdendo sua cor, apagando-se sem nos assustar, à medida que foi ganhando cor uma responsabilidade inédita, diferente, impensável. Em cada um daqueles casos, foi aparecendo aos poucos, com a extensão do tempo de convivência entre nós, um sujeito novo, vivo, capaz de, ao seu modo e na sua medida, surpreender com suas respostas de sociabilidade.

Fomos verificando que a simples oferta de uma rede de acompanhamento para onde pudesse endereçar seu sofrimento e onde pudesse entregar as pistas de sua solução modificava o que até então tínhamos aprendido nas teorias macabras sobre os loucos infratores. Estávamos entusiasmados pelo encontro com uma nova possibilidade de trabalho, ali para onde a nossa ignorância tinha nos conduzido. Os pacientes judiciários, os loucos infratores, foram aos poucos organizando um modo de tratar sua perturbação e se apresentando como sujeitos que respondem pelos seus atos na medida de sua singularidade, capazes de outras respostas do que aquelas imaginadas pela presunção de sua periculosidade.

Não recuar diante do que a experiência ensinava: uma orientação ética!

Apostávamos na construção responsável de uma prática intersetorial, feita por muitos, que pudesse sustentar, na trama de seu tecido, o que esses sujeitos e tantos outros, na busca de uma solução que fizesse cessar um sofrimento insuportável, poderiam nos ensinar sobre o modo de tratamento jurídico, clínico e social que desse suporte e ampliasse os seus recursos para encontrar no mundo um lugar onde sua diferença tivesse cabimento.

\section{2 - Programa de Atenção Integral ao Pacien- te Judiciário Portador de Sofrimento Mental Infrator do Tribunal de Justiça de Minas Gerais - PAI-PJ \\ No dia dois de março de 2000, a} Corregedoria do Tribunal de Justiça de Minas 
Gerais implantou o projeto-piloto, para dar continuidade ao acompanhamento dos 15 casos da pesquisa e de quaisquer outros em que o réu ou condenado fosse portador de sofrimento mental, com processos tramitando nas varas criminais da comarca de Belo Horizonte. O projeto nasceu com a denominação inicial de "Projeto de Acompanhamento Interdisciplinar ao Paciente Judiciário" (PAI-PJ), e sua função era realizar a mediação entre o tratamento e o processo jurídico, até o tempo da inserção social das pessoas. Dito de outro modo, atuávamos junto aos Juízes Criminais estabelecendo a conexão com a rede pública de saúde, antes e depois da sentença, desde o início do processo criminal até a sua extinção, em todas as suas fases.

Os casos foram chegando pouco a pouco, à medida que corria, de boca em boca, que o projeto piloto estava intermediando a tensão existente junto às instituições de saúde e que realizava uma função mediadora, com algum êxito, no encaminhamento e no acompanhamento dos casos junto às instituições de tratamento em saúde mental de pacientes judiciários. Começavam a aparecer as primeiras indicações para acompanhamento na rede ambulatorial.

O fantasma da periculosidade voltava a rondar as equipes interinstitucionais. E se estivéssemos enganados? Afinal, por que deveríamos acreditar nas respostas da loucura? Estaríamos todos delirando, ousando acreditar que o paciente judiciário pudesse demonstrar a sua responsabilidade em condições de relativa liberdade?c

Mais uma vez, a orientação nos veio das pistas de sujeito. Um paciente judiciário, L.V., ao saber da sua liberação, disse-nos: "Mas eu sou de altíssima periculosidade! Se o juiz está de acordo com minha liberação, esta deve de ser uma liberdade vigiada, uma liberação condicional, para que o Juiz me acompanhe e possa chegar junto em caso de perigo.” E assim foi feito. ${ }^{\mathrm{d}}$

O que L.V. nos indicava é que o retorno ao convívio social não é desprovido de angústia, haja vista a situação dramática dos egressos de todo sistema penitenciário. O sentido do desalojamento, o sentir-se isolado, excluído, fora do lugar, um estranho no ninho na volta para casa são alguns dos inúmeros relatos de egressos do sistema. O que L.V. fez foi nos ensinar, mais do que avisar, que a saída não era sem dificuldade, solicitando nossa secretaria no sentido de ampliar os recursos à sua disposição, caso o embaraço de seu sofrimento resolvesse perturbar o percurso de sua medida.

Cada vez mais, aprendíamos com a experiência da loucura, aprendíamos a considerar sua palavra, seus avisos, suas respostas, ainda que pudessem parecer um tanto quanto desprovidos de razão. De fato, o que os sujeitos nos ensinavam é que a vida nem sempre é razoável ou se dirige precisa através de estratégias racionais. Fernando Pessoa disse: "navegar é preciso, viver não é preciso”; portanto, estávamos decididos, pelos resultados alcançados no acompanhamento dos casos, a nos orientar pela bússola que cada paciente trazia em seu bolso.

Em dezembro de 2001, o Tribunal de Justiça de Minas Gerais, por iniciativa pioneira do Desembargador Gudesteu Biber Sampaio, Presidente do Tribunal de Justiça de Minas

c Dizem, no campo da saúde mental, que, para ser realmente um delírio, é necessário que seja de um sozinho. Quando o delírio for compartilhado por mais de um, transforma-se em obra.

d A partir da solução apresentada por L.V., buscamos encontrar os subsídios para a regulação da sua saída. Verificamos que, no antigo código de processo penal, a orientação normativa prevista no título V, que trata da execução das medidas de segurança, em seu artigo $n^{\circ} 767$, determinava que caberia ao Juiz fixar as normas que deverão ser observadas durante a liberdade vigiada, podendo inclusive entregar ao indivíduo sujeito a ela uma caderneta, da qual constarão suas obrigações durante o tempo de cumprimento da medida. (LEGISLAÇÃO BRASILEIRA, 1999:129). 
Gerais e o Desembargador Murilo José Pereira, Corregedor-Geral de Justiça do Estado de Minas Gerais, a experiência-piloto foi transformada em um programa - Programa de Atenção Integral ao Paciente Judiciário - PAI-PJ, através da portaria conjunta $n^{\circ}$ 25/2001 do Tribunal de Justiça de Minas Gerais.

O programa firmou-se através de uma parceria permanente com o Projeto de Saúde Mental do Município de Belo Horizonte, o Ministério Publico, o Centro Universitário Newton Paiva e os diversos recursos institucionais, dentre outros disponíveis na cidade. A experiência da loucura ensinava sobre a pluralidade razoável de soluções de sociabilidade. Estas se alinhavavam entre os diversos atores institucionais, que funcionavam como uma secretaria permanente na atenção ao louco infrator.

Para realizar a tarefa da secretaria, numa rede intersetorial, lançamos mão da metodologia de atenção integral, através das rodas de conversa, recolhendo com essa ferramenta os indicadores para movimentar o acompanhamento atento e cotidiano do caso. O programa funciona como um dispositivo conector, agregando em torno do acompanhamento do paciente judiciário as ações da autoridade judicial, do Ministério Público, da rede de saúde mental e social de cada caso.

\section{1 - Cotidiano do funcionamento:}

O Programa, em resumo, tem por função a oferta do acompanhamento integral ao paciente judiciário portador de sofrimento mental em todas as fases do processo criminal. Ocorre de modo intersetorial, através da parceria do Judiciário com o Executivo e com a comunidade, de forma geral, promovendo o acesso à rede pública de saúde e à rede de assistência social, de acordo com as políticas públicas vigentes, na atenção integral ao portador de sofrimento mental.

Os casos são encaminhados por meio de ofício dos juízes criminais, determinando que sejam acompanhados pelo programa. Chegam, também, encaminhados por familiares, estabelecimentos prisionais, instituições de tratamento em saúde mental e outros parceiros. A pessoa encaminhada responde como réu a um processo criminal, mesmo se ainda não houver o incidente de sanidade mental instaurado no processo, realiza-se uma avaliação jurídica, clínica e social do caso, e solicita-se ao juiz criminal autorização para o acompanhamento do caso. Sendo autorizado, este é encaminhado à rede pública de saúde mental, se ainda não estiver em tratamento. Junto com a rede, construir-se-á o projeto terapêutico e social para o paciente, o qual será constantemente revisto e reconstruído, de acordo com as indicações do próprio sujeito. $\mathrm{O}$ acompanhamento ocorre durante o processo criminal e continua depois da sentença, que pode ser uma pena ou medida de segurança, seguimos acompanhando o sujeito até a finalização da execução penal.

A equipe interdisciplinar do programa é composta de psicólogos judiciais, assistentes sociais judiciais, assistentes jurídicos e estagiários em psicologia. Os estagiários atuam como acompanhantes. Este acompanhamento favorece as possibilidades de circulação pela cidade, ampliando os laços sociais como forma de tratar o sofrimento.

Os assistentes sociais judiciais realizam o estudo do caso e apresentam ao paciente judiciário os recursos que visam à garantia dos direitos fundamentais e sociais, sempre na medida em que o caso indique.

Os psicólogos judiciais realizam o acompanhamento sistemático dos pacientes, buscando escutar e acolher o que para cada um funciona como modo de tratar o sofrimento, encaminhando-os aos pontos da rede da cidade de Belo Horizonte indicados para favorecer a ampliação dos recursos de tratamento, aos quais o sujeito poderá recorrer nos momentos de crise ou embaraço.

Os assistentes jurídicos estudam os autos, acompanham os andamentos processuais, 
informam ao paciente judiciário sobre sua situação processual, acompanhando-os durante as audiências e formatam os ofícios que são encaminhados ao juiz com base nos pareceres interdisciplinares da equipe e da rede constituída em cada caso.

O PAI-PJ através desta equipe interdisciplinar-psicólogos, assistentes sociais judiciais e assistentes jurídicos - além de secretariar cada caso na sua relação com a vida na cidade, funciona como um serviço auxiliar do Juiz, subsidiando a decisão judicial e conectando aos autos os relatórios cujo material foi tecido no trabalho com os diversos parceiros fora do sistema jurídico: trabalhadores da saúde mental, de organizações e entidades sociais, familiares, dentre outros.

Dessa forma, a autoridade judicial, integrando a sua ação ao conjunto de todas as outras necessárias ao funcionamento da execução penal, realiza efetivamente sua função jurisdicional de acompanhamento da sanção penal aplicada, promovendo os meios para que o paciente judiciário possa acessar os recursos necessários - sociais, de tratamento ou mesmo jurídicos, na invenção de uma laço social que lhe convenha e que seja razoável, durante o tempo em que responde pelo seu ato fora da lei.

\section{2 - Inovações no acompanhamento do lou- co infrator a partir desta experiência}

$\mathrm{O}$ que realmente se tornou inovador foi a possibilidade inédita de colocar no centro dessa rede de atenção e cuidados o sujeito, acompanhando sua trajetória e secretariandoo de perto como mais um recurso do qual ele pode se servir e ao qual pode se conectar para se desembolar dos embaraços que a sua singular diferença pode lhe apresentar nas suas relações de convivência.

A proposição do projeto pretendeu tratar a crise instalada entre a justiça e a saúde mental; contudo, a novidade que se revelou desse tratamento da crise foi a possibilidade inédita de dispensar o manicômio judiciário como lugar para os loucos infratores. A resposta encontrada pela crise substituiu a prática reacionária do manicômio pela inclusão dessa população nas políticas públicas de atenção à saúde mental, sem desprezar a importância do tratamento jurídico na solução de cada caso. Essa política inovadora enfim se integra aos princípios constitucionais e fundamentais dos direitos humanos, às diretrizes da reforma psiquiátrica indicadas na lei 10.216/2001 e essencialmente resgata a humanidade do portador de sofrimento mental infrator, conforme orientou Lacan para que nossa prática "corresponda a esperança que palpita em todo ser condenado de se integrar num sentido vivido. ${ }^{3,4,5}$

Deste modo, criaram-se as condições necessárias para que o paciente judiciário receba seu tratamento em saúde mental e tenha um acompanhamento de sua sanção penal de modo individualizado, particular, na medida de sua possibilidade, capacidade e responsabilidade.

Apresentamos como fundamental a abertura para um trabalho intersetorial, multidisciplinar, em condições de dispensar o véu da periculosidade que encobriu, por mais de um século, as possibilidades inéditas do sujeito, louco infrator, que desde sempre deveria ter sido considerado como um sujeito de direitos. De algum modo, estamos esclarecidos de que o caminho passa pela necessidade de transmitir e assegurar a cada um que é considerado paciente judiciário de que pode ser dispensado de se esconder sob as vestes da periculosidade, de que pode ser chamado a se apresentar do seu jeito e responder publicamente pela sanção penal que lhe foi aplicada, fazendo uso dos espaços de convivência abertos da cidade, através dos múltiplos meios para ampliar seus recursos de sociabilidade.

Não estamos entre aqueles que acreditam que a questão do louco infrator é um problema exclusivo da saúde publica, que a execução da sanção penal deve passar por fora do campo de competência do direito penal, sendo 
o Juiz apenas um burocrata que recebe e anexa ao processo as comunicações encaminhadas pelos serviços de saúde, onde o paciente judiciário faz o tratamento. A nossa experiência ensina que o fato de alcançar o direito de ter acesso ao tratamento de saúde que corresponde à singularidade clínica e social do cidadão não o dispensa do dever de responder pelo seu crime, comparecendo às audiências, atravessando os rituais dos dispositivos jurídicos, subjetivando sua posição na relação com a lei que organiza o social no qual habita.

A possibilidade de responder pelo crime cometido é uma condição humanizante, um exercício de cidadania que aponta para a responsabilidade e para a capacidade do sujeito de se reconhecer como parte de um registro normativo que serve para todos. Responder pelo seu crime é um modo de inclusão, pois insere o sujeito dentro do 'guarda-chuva' da lei, que abriga a todos sob o seu manto. Muitas discussões devem e podem ser feitas para mudar algumas das descabidas orientações normativas, como a soberania da pena de privação da liberdade como a rainha das respostas punitivas do Estado Brasileiro - uma condição totalmente desumana e ineficaz no sentido da inserção social.

A presunção da periculosidade é outro absurdo que deveria desaparecer dos textos normativos, assim como a indeterminação do tempo da medida de segurança e a própria lógica das medidas de segurança. Contudo, jamais as modificações da lei podem caminhar no sentido de tratar o louco como uma exceção, um caso apenas para a saúde devido à sua condição menos humana, à sua patologia. Nossa experiência não nos dirige nessa direção.

O PAI-PJ, enquanto um dispositivo conector, busca orquestrar as múltiplas ações intersetoriais e, para tanto, tenta encontrar, nas orientações normativas ou nas suas lacunas, uma forma de integralizar as lógicas discursivas e funcionais centrífugas, através da amarração dos consensos percebidos entre os vári- os setores que trabalham com o paciente judiciário. Ainda que cada serviço tenha uma especificidade que o individualiza por meio de um funcionamento regulado por normas e paradigmas diversos, é preciso trabalhar para caminharmos separados, mas numa mesma direção.

A direção de todos deve ter apenas uma orientação: o laço do sujeito com a sociedade, de tal modo que sua convivência no espaço público seja razoável. A Justiça, o Ministério Público, a rede de saúde mental, os familiares e, principal e fundamentalmente, o sujeito, paciente judiciário, sossegam quando essa solução se mostra possível. Essa é a orientação que indica a todos os atores desse sistema uma direção.

A ação do PAI-PJ visa a alcançar, no constrangimento do encontro entre os diversos atores e instituições, a efetividade na garantia dos direitos, na redução da violência e na acessibilidade ao projeto de saúde singularizado. Ao final podemos, através desse coletivo de ações coadunadas pela mesma finalidade, promover uma execução penal em constante movimento, sempre atualizada na aplicação do melhor acompanhamento, visando a garantir seu fim último: um laço social satisfatório para o sujeito e razoável para a sociedade de forma geral.

Dessa forma, fomos alcançando o impensável, tornando possível que o portador de sofrimento mental cumpra sua sanção penal fora do manicômio judiciário. Através de um trabalho dinâmico, feito por muitos. Percebemos que, quando se segrega o louco infrator no manicômio judiciário, cada um dos operadores do sistema penal, penitenciário e de saúde mental que circulam o louco infrator fica também isolado, tendo que responder por decisões extraídas da letra fria da lei e de relatórios monótonos enviados, na melhor das hipóteses, quando a lei determina. O sujeito está escondido, isolado, ninguém sabe do que ele é capaz, foram cortadas as pontes que poderiam 
transmitir sua potencialidade de novas respostas. Ele é mantido no isolamento, por tempo indeterminado, porque não se tem acesso à sua singularidade.

Aquela invenção de uma solução compartilhada para a crise entre justiça e saúde, em 1999, informou-nos que a responsabilidade de cada um, num trabalho feito por muitos, permitiu que o louco infrator finalmente pudesse mostrar aos muitos dessa rede do que ele era capaz. Estourou a bolha da presunção da periculosidade que o enjaulava e caiu no mundo. Movimentou a rede, saiu do isolamento, da invisibilidade e do silêncio e exigiu de juízes, de promotores, de trabalhadores da saúde, da justiça, do Ministério Público, dos familiares e da sociedade que déssemos nossa resposta diante da inevitabilidade da convivência com ele.

Nos dias 1 e 2 de julho de 2002, um coletivo formado por representantes do poder judiciário, da saúde, do Ministério Público e de movimentos sociais reuniu-se para construir o Primeiro Seminário Nacional cujo tema foi “A atenção ao louco infrator: uma questão de Justiça.” Esse seminário foi responsável por reunir inúmeros atores de Belo Horizonte, estabelecendo parcerias e ações conjuntas na construção de uma política responsável e relativa ao compromisso de sustentar, na rede aberta da cidade, o tratamento jurisdicional, clínico e social do louco infrator. Ao final do evento, foi aclamada por unanimidade a "Carta de Minas: A cidadania do louco infrator é um compromisso de toda sociedade”.

Desde então, Belo Horizonte se tornou a primeira cidade de Minas Gerais, do Brasil (e também destaque no cenário internacional) a tratar os loucos infratores na rede aberta da cidade, conjugando responsabilidade e inserção social, através de uma parceria com os diversos atores e instituições que cruzam esse campo.

Nesse mesmo mes, Pedro Gabriel Delgado, Coordenador do Programa Nacional de
Saúde Mental do Ministério da Saúde, em sua exposição ao final do I Seminário de Reorientação dos Hospitais de Custodia e Tratamento, falou sobre a "Reforma Psiquiátrica e o atendimento ao paciente infrator: o feito e o por fazer".

“Algumas experiências apresentadas e debatidas no seminário - como a do PAI-PJ, do Tribunal de Justiça de Minas Gerais - vêm demonstrando que é possível o atendimento do paciente mental infrator fora do Hospital de Custódia e Tratamento Psiquiátrico (HCTP), em serviço de atenção diária ou ambulatórios. Este deve ser um objetivo a se perseguir, no rumo da superação e substituição progressiva destes estabelecimentos." 6

Esse foi o caso de Goiás, amplamente discutido naquele seminário, pois havia uma pressão política para a construção de um manicômio judiciário no terreno onde se localizava o lixão da cidade. Na tentativa de construir coletivamente uma alternativa para a questão do louco infrator em Goiás, o Ministério da Justiça e o Ministério da Saúde, numa ação intersetorial, convidaram a coordenação do PAI-PJ do Tribunal de Justiça de Minas Gerais para assumir a direção do censo clínico, jurídico e social referente à situação dos portadores de sofrimento mental do Estado de Goiás, bem como o processo necessário à implantação de um programa de atenção integral ao louco infrator, de acordo com as circunstâncias do local, inspirado nas diretrizes e nos princípios em funcionamento da experiência pioneira de Belo Horizonte, conforme publicado na portaria $\mathrm{n}^{\circ} 36$ do Diário Oficial da União, em $1^{\circ}$ de julho de 2003.

Esse trabalho conjunto, interministerial e interestadual, culminou na apresentação pública do projeto de implantação de programa semelhante em Goiás, o PAILI, em julho de 2004. Contudo, devido ao jogo político de forças atuantes naquele momento, esse projeto somente foi efetivado em 26 de outubro de 2006. As possibilidades, dificul- 
dades e os entraves encontrados no trabalho de implantação de um programa de atenção ao louco infrator naquele estado, confirmaram a importância da prescrição do relatório final de reorientação dos hospitais de custódia e tratamento psiquiátrico, quando afirma que o encaminhamento dessa população para a rede pública de saúde exige de todos os atores envolvidos "o desafio do fortalecimento da rede de atenção extra-hospitalar e a capacitação dos profissionais da saúde e da justiça para o redirecionamento da assistência ao louco infrator. ${ }^{6}$

A experiência do PAI-PJ ensina que as soluções relativas ao tratamento do louco infrator não se encontram na forma autônoma nem podem ser postas em prática a poucas mãos; exigem o comprometimento coletivo dos diversos atores que atravessam seu campo de intervenção. É assim que tem sido possível, nos dez anos de funcionamento do PAI-PJ, manter como prioridade absoluta que o tratamento dos loucos infratores seja realizado na rede SUS, segundo os princípios orientadores de atenção psicossocial ao portador de sofrimento mental, desenhados pelo Ministério da Saúde.

Apesar dos constrangimentos relativos ao jogo de forças em ação nas arenas de discussão, próprios da natureza heterogênea dos discursos atuantes, para alcançar esse fim é preciso sustentar, como horizonte, a luta decidida através de uma trajetória muito particular, nem sempre iluminada, mas que considera a complexidade que amarra as singularidades normativa, jurídica, social e clínica relativas a cada caso.

O PAI-PJ também foi apresentado na França, em novembro de 2005, num evento que reuniu diversas instituições, profissionais e pesquisadores para uma reflexão que levou o nome do evento: "Une reflexion internationale sur la question de la responsabilité.” Em fevereiro de 2006, o programa PAI-PJ foi tema de conferência apresentada na Ecole d'Hautes Etudes Sciences Sociales - Paris, e ainda em maio deste mesmo ano, o programa foi apresentado na Grécia - Atenas, no Fórum Social Europeu. O Programa retornou à discussão internacional, ao apresentar sua experiência juntamente com as experiências da Suíça, da Itália e da França, num colóquio, sobre o tema "Dangerosités a dechiffrer: pour quels traitements?”, realizado em Paris, em novembro de 2008.

A repercussão do programa PAI-PJ parece ser tributária das novas referências levadas ao espaço coletivo das discussões sobre o tema do louco infrator. Contudo, estamos cientes de que não existe uma receita de bolo. Cada cidade deverá tomar para si o dever de se apropriar dessas referências para integrálas e ajustá-las ao contexto e aos recursos locais dispostos naquele território. A reforma necessária e desejável deve acontecer no município do portador de sofrimento mental, pois lá estão os elementos que dão suporte à sua rede de sociabilidade. Enfim, a experiência transmitida no encontro com os portadores de sofrimento mental que cometeram algum crime não nos permite recuar diante da necessidade imperativa de reunir os diversos atores e construir diretrizes nacionais para a construção de uma política de atenção integral ao paciente judiciário, portador de sofrimento mental infrator. A nossa luta cotidiana é na direção de criar os meios necessários para tornar razoável a cidadania do louco infrator, entre nós.

\section{3 - Alguns dados do Programa (junho/2009)}

O Programa de Atenção Integral ao Paciente Judiciário - PAI-PJ, em dez anos de funcionamento, já acompanhou 1058 processos criminais, numa parceria contínua entre a justiça, o Ministério Público, a rede pública de atenção em saúde mental e os dispositivos sociais da rede aberta da cidade. Foram acolhi- 
dos, nesse espaço mediador, 755 cidadãos, constituindo em cada caso a invenção necessária, através desses dispositivos conectores, produzindo o tratamento necessário ao sofrimento mental, buscando sua inserção na sociedade até cessar suas relações com a justiça. Deste total, 489 casos já foram desligados e 266 casos encontram-se em acompanhamento.

Atualmente, 228 encontram-se em liberdade realizando tratamento nos dispositivos substitutivos ao manicômio e residem junto aos familiares ou em residências terapêuticas do município. Estes sujeitos, de modo geral, fazem o seu tratamento na rede aberta da cidade e apresentam-se regularmente à justiça para demonstrar sua responsabilidade na cidade. 18 pacientes, desses 228, estão recebendo atenção 24 horas, nos serviços substitutivos em saúde mental do município, devido ao momento de grande instabilidade e perturbação no seu quadro clínico, sendo acolhidos naquelas instituições que oferecem hospitalidade dia e noite para dar tratamento ao sofrimento da crise. Esse é um dado que sofre variações constantemente, pois o paciente pode sair e retornar ao serviço de atenção 24 horas à saúde mental, de acordo com as contingências clínicas, caso a caso.

Dos 126 casos sentenciados com medida de segurança e acompanhados pelo programa, apenas 25 possuem medida de segurança de internação, 87 cumprem medida de segurança ambulatorial e 14 casos já se encontram em liberação condicional da medida de segurança.

Acompanhamos, ainda, 77 casos que não receberam sentença, mas que já se encontram inseridos na rede de saúde mental.

Apesar de as pessoas em cumprimento de pena não corresponderem aos casos designados na portaria $n^{\circ} 25 / 2001$, que cria o PAIPJ, alguns juizes têm solicitado atenção da nossa equipe para assegurar a esses indivíduos o seu direito ao tratamento, quando, por alguma contingência durante o cumprimento de sua pena restritiva de liberdade, entraram em crise, apresentando grande sofrimento mental.
Nesses casos, a equipe do PAI-PJ tem acompanhado o tratamento do paciente, que acontece, de modo geral, junto ao CAPS (Centro de Atenção Psicossocial) do município onde a penitenciária está localizada. Hoje, encontramse nessa situação 63 pessoas: 48 sentenciadas com pena (10 cumprem pena restritiva de direitos e 38 pena privativa de liberdade), $8 \mathrm{em}$ livramento condicional e 7 casos com processos já encerrados aguardando formalização. Além dos 266 casos em efetivo acompanhamento, outros 23 casos estão sendo avaliados quanto à possibilidade de acompanhamento pelo programa.

Pesquisando a situação dos casos encerrados, registramos uma reincidência em torno de $2 \%$, relativa a crimes de menor gravidade e contra o patrimônio, e, em dez anos de trabalho, não temos registro de reincidência de crime hediondo, que ensejasse o retorno do fantasma da periculosidade que, via de regra, assombra o cuidado e a convivência com estas pessoas.

Para encerramento dos casos, como prerrogativa legal, é solicitado o exame de cessação de periculosidade, podendo assim o sujeito cessar a "dívida" com a justiça. Os laudos dos peritos psiquiatras designados pela autoridade Judicial para realização do exame de cessação de periculosidade, de maneira geral, têm confirmado a ampliação dos recursos de tratamento do indivíduo e as suas diversas respostas de laço social. Antes do acompanhamento pelo PAI-PJ, os casos cumpriam medida de segurança no modo "prisão perpétua", perdendo seus laços sociais definitivamente. A média de tempo de internação no Manicômio Judiciário Jorge Vaz, em Barbacena, tem sido de 20 anos. Hoje, com a oferta deste acompanhamento feito por muitos, a média de tempo entre a entrada do paciente judiciário no programa e a sua saída do sistema jurídico, tem sido de 5 anos, com a cessação de periculosidade confirmada pelos peritos, considerando a demonstração pública da sua res- 
posta razoável de laço social.

Todos os casos são acompanhados pelo programa em conexão com a rede pública de saúde, acessando, sempre que necessário, os diversos recursos indicados como uma solução de sociabilidade.

\section{REFERÊNCIAS}

1. Costa. V. A. A história dos pacientes judiciários no InstitutoRaul Soares. Belo Horizonte, UNP, 2000.

2. Barros, F.O. Relato da experiência da pesquisa com os pacientes judiciários. Belo Horizonte: Mimeo, 1999.

3. Lacan, J. Da psicose paranóica em suas relações com a personalidade (1932). Rio de Janeiro: Forense-Universitaria, 1987.

4. Lacan, J. Escritos. Rio de Janeiro : Jorge Zahar Editor. 1998

5. Lacan, J. Outros Escritos. Rio de Janeiro : JZE.

6. Ministério da Saúde/Ministério da Justiça. Seminário Nacional para Reorientação dos Hospitais de Custódia e Tratamento Psiquiátrico : Relatório Final. Brasília:. setembro de 2002.

Recebido em 22 de agosto de 2009. Modificado em 02 de janeiro de 2010. Aceito em 30 de janeiro de 2010. 